\title{
Single-Step Fabrication of a New Maxillary Obturator Prosthesis
}

\author{
Muhammad Waseem Ullah Khan ${ }^{1 *}$, Asif Ali Shah ${ }^{2}$ and Aliya Fatima ${ }^{3}$ \\ ${ }^{1}$ Assistant Professor of Prosthodontics, Prosthodontics Department, Punjab Dental Hospital/de'Montmorency \\ College of Dentistry, Fort Road, Lahore, Pakistan \\ ${ }^{2}$ Professor of Prosthodontics, Prosthodontics Department, Punjab Dental Hospital/de'Montmorency College of \\ Dentistry, Fort Road, Lahore, Pakistan \\ ${ }^{3}$ FCPS Resident, Prosthodontics Department, Punjab Dental Hospital/de'Montmorency College of Dentistry, Fort \\ Road, Lahore, Pakistan
}

Received: November 28, 2014; Accepted: March 24, 2015; Published: April 10, 2015

*Corresponding author: Dr. Muhammad Waseem Ullah Khan, Orthodontics Dental Centre, 5-B Gulberg II, Lahore, Pakistan, Tel: 03-334-844-939; Email: veritarian@yahoo.com

\begin{abstract}
Patients with acquired maxillary defects suffer from disturbances in mastication, speech and social activities. Obturator prostheses eliminate these problems and allow the patients to function normally in the society. A new maxillary obturator prosthesis was constructed for an old obturator wearing patient using a pick-up impression technique and bite registration with his previous prosthesis. The obturator was inserted at the very next clinical visit saving the patient from multiple appointments.
\end{abstract}

Keywords: Hemimaxillectomy; Obturator; Prosthesis

\section{Introduction}

Surgical procedures to eradicate carcinomas of head and neck region usually leave behind large tissue defects and it becomes a challenging task for the maxillofacial prosthodontist to rehabilitate these patients to optimum function and esthetics $[1,2]$. The patients having partial or complete maxillary resections face a variety of difficulties including defective mastication, swallowing, speech and social interaction $[3,4]$.

The partially dentate maxillary defects are classified according to Aramany's classification and are treated successfully by taking support from the natural teeth $[5,6]$. Maximum number of remaining natural teeth or dental implants should be engaged in the obturator design to gain sufficient support, retention and stability for the prosthesis $[4,7,8]$. Unfortunately, in many cases the little amount and poor quality of residual bone available after resection and radiotherapy along with economic constraints of patients preclude the use of dental implants. In these cases the prosthodontist has to resort to conventional physical methods to maximize the support, retention and stability [9].

The present case report describes a simple, economic and reliable single step procedure for the construction of a new obturator prosthesis using the previous obturator as an impression tray and bite recording template. This technique is a useful way to limit the multiple patient visits required for the construction of a conventional obturator.

\section{Case Report}

A 36 year old male patient presented to the outdoor of Prosthodontics department, de'Montmorency College of Dentistry / Punjab Dental Hospital, Lahore. The patient had a history of Ameloblastoma in the right maxilla for which he had undergone a hemimaxillectomy type of surgical resection ten years ago. The patient had an Aramany Class I defect and was using obturator prosthesis for the last ten years. His chief complaints with the previous obturator were its looseness, foul smell and unaesthetic appearance. The patient was a carpenter by profession and medically and physically fit.

On extra oral examination there was a tissue contracture visible on the right side of face (Figure 1). On intra oral exam it was observed that the left maxillary quadrant was intact with all

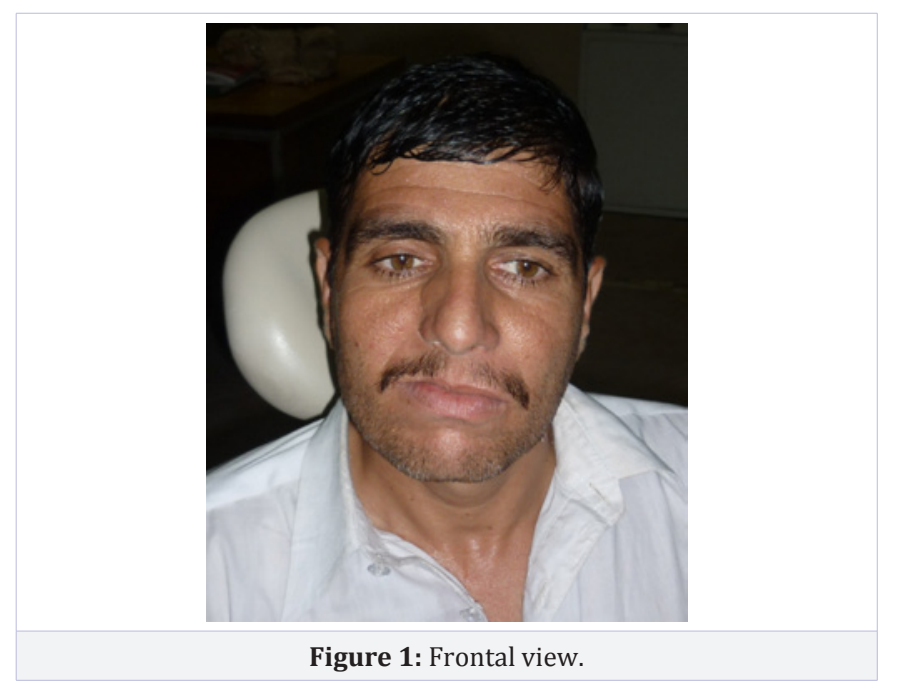


the teeth present except left upper central incisor. The left upper lateral incisor however was carious and required restoration (Figure 2,3). The mandible had a full component of natural teeth and the oral hygiene was fair. The patient had normal mouth opening and jaw movements. A mature maxillary Aramany Class I defect on the right side was present with the loss of all teeth from left upper central incisor to right upper third molar.

The defect had a communication with the nasal cavity and mild lateral undercuts were present (Figure 2). The previous obturator was an all acrylic ill fitting removable prosthesis. The support and retention was inadequate but it had stable occlusal contacts with the opposing dentition (Figure 3). The ten years old acrylic denture base showed signs of disintegration such as foul smell, discoloration and staining.

After thorough evaluation of the patient it was decided that new acrylic obturator prosthesis will be fabricated for him using his old obturator both as an impression tray and bite recording

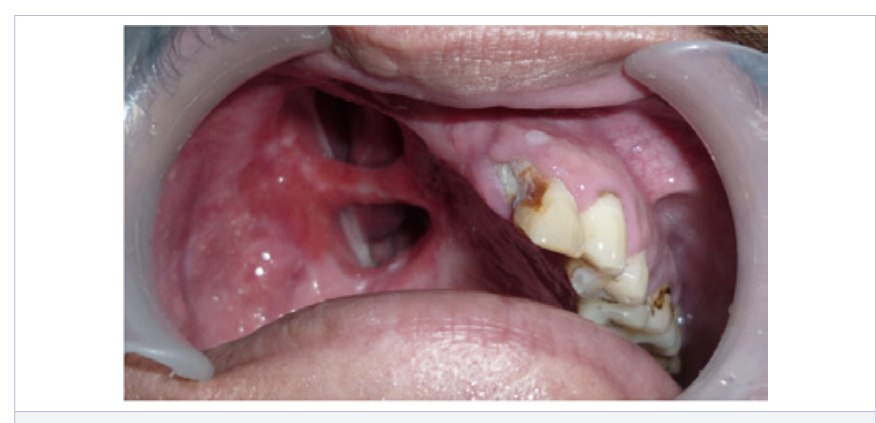

Figure 2: The defect.

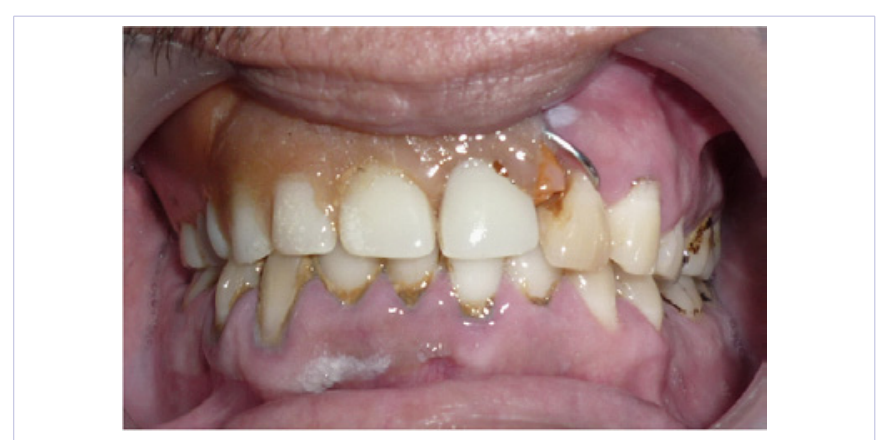

Figure 3: Old prosthesis in situ.

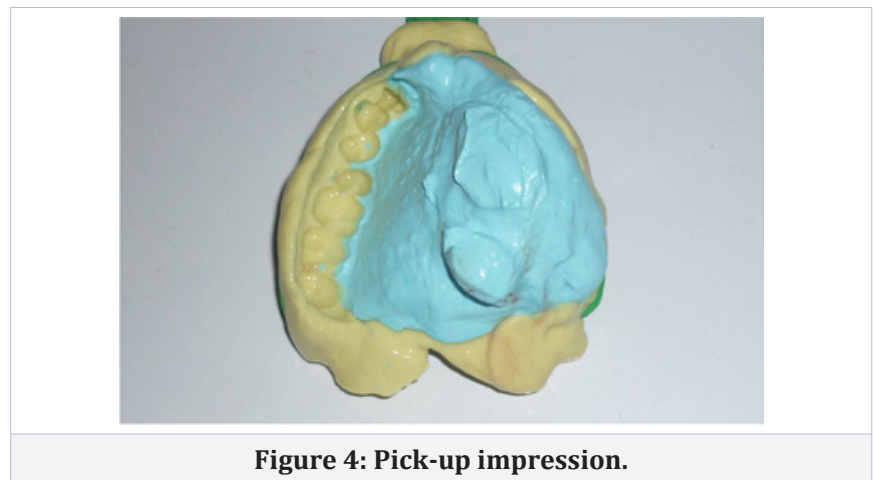

template. A cast partial framework and/or implant supported prosthesis were not selected because of financial constraints of the patient.

\section{Technique}

1. The previous prosthesis was checked for overextensions and underextensions with pressure indicating paste. No underextensions were noted and the overextensions were removed with an acrylic trimming bur.

2. Impression with a thin layer of Zinc oxide-Eugenol impression paste was taken in the same obturator using closed mouth impression technique (see discussion)

3. Stock tray was not used for the impression because it doesn't precisely adapt to the defect and its modification to adapt to the defect takes some extra time. Also bite registration is not possible until a temporary or permanent base plate with wax rims is constructed over the stock tray impression which will need an additional visit.

4. With obturator in situ, bite registration was done using an interocclusal wax wafer record in centric occlusion. This record was removed carefully and preserved for future articulation.

5. Now a pick-up impression of the upper arch with the obturator in situ was taken in a stock tray using irreversible hydrocolloid alginate impression material (Figure 4) and poured in type IV gypsum.

6. Lower impression in a stock tray with irreversible hydrocolloid alginate material was taken and poured in type IV gypsum.

7. The interocclusal bite record was used to articulate the upper and lower casts along with the previous obturator.

8. Neutral zone was not recorded for this patient because he was partially dentate. Natural opposing teeth guided the placement of artificial teeth and the direct retainers usually provide sufficient retention for the prosthesis minimizing the need for recording neutral zone.

9. The obturator was now removed from the articulator and returned to the patient for use until a new one was fabricated.

10. Surveying of the upper cast was done on a surveyor to determine the favorable and utilizable tooth and tissue undercuts. A suitable path of insertion was selected for the obturator.

11. On the articulated casts, wrought wire clasps on left upper lateral incisor, first premolar and first molar were made.

12. Anterior teeth must be placed according to smile line but it wasn't possible in this case because of skipping a separate jaw relation step where smile line is recorded on wax rims so they were placed for denture stability with minimum overjet and overbite. However, incidently 


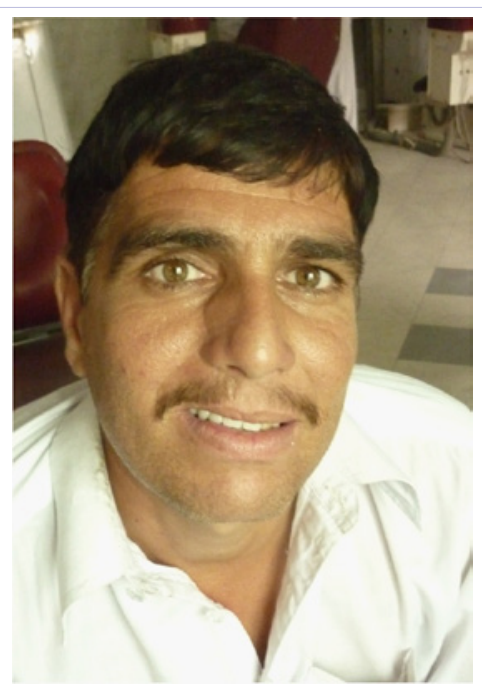

Figure 5: Frontal view with new obturator.

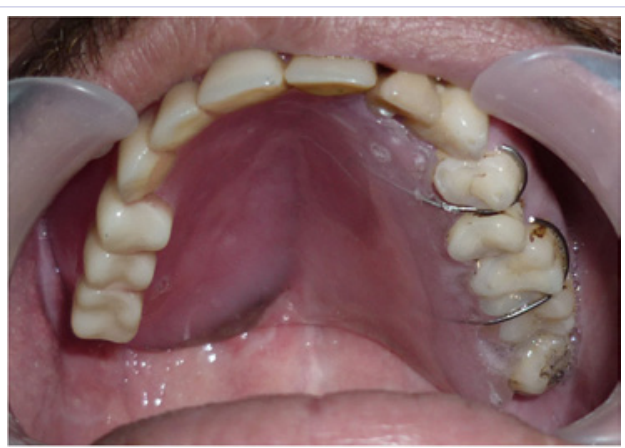

Figure 6: New obturator in-situ showing optimum retention.

the final outcome was pleasing and the curve of the upper artificial teeth was in harmony with the smile line (Figure 5) while the posteriors were placed in maximum intercuspation with the opposing teeth.

13. Post dam carving and final wax up with full palatal coverage was done. The palatal contour on the defect side was formed as a continuation of the palatal form on the normal side.

14. The defect was not too deep i.e. just 2-3 mm deeper than the level of the residual hard palate (Figure 2). The bulk and weight of the prosthesis was not much of a concern for retention of prosthesis so the construction of a Hollow bulb was not considered.

15. After laboratory processing, finishing and polishing the new obturator was delivered to the patient in the next visit after three days (Figure 5,6).

16. Composite filling of left upper lateral incisor was done just before insertion. During insertion the tissue surface was checked for intimate tissue contact with a pressure indicating paste and occlusal corrections were performed with articulating ribbon. Oral and denture hygiene instructions were given to the patient and called for follow up visit one week after the insertion.

17. On the follow up visit the patient presented with no complaints. Oral and denture hygiene instructions were reinforced and the patient was set on a 6 month periodic recall visit for follow up.

\section{Discussion}

A maxillary obturator prosthesis was fabricated for a patient with hemimaxillectomy defect. The patient was a satisfied old obturator wearer but after ten years some tissue changes had occurred making the previous obturator loose. The acrylic had started disintegrating giving foul smell and poor appearance. Financial constraints of the patients limited our treatment options and precluded the selection of cast partial framework or treatment with dental implants so a simple acrylic obturator was planned for the patient.

Usually the material of choice for such impressions is an elastomer because of its elasticity and hydrophobic nature which is of benefit in most post-radiation, xerostomic maxillectomy patients. Zinc oxide-Eugenol is generally avoided because of its inability to be retrieved from sharp undercuts, rigid nature and absorption of moisture during setting. But author's preference for recording the palate and the defect surface was ZnO-Eugenol because in this particular case, the defect was neither narrow / constricted nor had sharp undercuts. Infact, defect was wide open with little tissue undercuts and a fairly straight path of insertion and removal. In the author's experience and opinion, there were no such undercuts in this particular defect where Zinc oxide-Eugenol would get stuck and break upon retrieval which is also visible in the resultant final impression (Figure 4). It was also selected because its general ability to record very fine tissue details with only $0.5-1 \mathrm{~mm}$ film thickness in a close fitting tray as in this case [10]. This provided intimate tissue contact of prosthesis with the denture bearing area enhancing both support and retention $[4,11]$. Salivary flow rate of the patient was normal so it also did not contraindicate use of Zinc oxideEugenol impression paste.

The pick-up impression was taken in irreversible hydrocolloid alginate impression material in a stock tray which recorded the rest of the arch and the remaining dentition. Bite record in the form on an occlusal wafer was recorded and used for mounting of the casts. These records were sufficient for the construction of a new obturator in the laboratory.

Basic principles of obturator construction were followed i.e. maximum extension of the denture base to maximize support, engaging a maximum number of teeth with wrought wire clasps for the necessary retention and carving of post dam to improve posterior palatal seal. There is a drawback in this technique that tooth try-in cannot be performed using this method.

Most of the patients having maxillofacial defects limit their social contact. They also don't prefer frequent visits to the dentist. Therefore, short and simple procedures should be adopted in treating such patients to save them from multiple unnecessary visits to the clinic as described in this case. 


\section{References}

1. Omondi BI, Guthua SW, Awange DO, Odhiambo WA. Maxillary obturator prosthesis rehabilitation following maxillectomy for ameloblastoma: case series of five patients. Int J Prosthodont. 2004; 17: 464-8.

2. Mahajan T, Abhishek J, Thanuja R, Jayaprakash K. Prosthetic rehabilitation of maxillectomy patient with immediate and post surgical obturators: a case report. Int J Dent Clin. 2011; 3: 96-7.

3. Irish J, Sandhu N, Simpson C, Wood R, Gilbert R, Gullane P, et al. Quality of life in patirnts with maxillectomy prosthesis. Head Neck. 2009; 31: 813-21.

4. Taira Y, Yanamoto S, Kawasaki G, Yamada S, Atsuta M. A detachable silicone obturator fitted after bilateral maxillectomy: a case report. Int Chin J Dent. 2007; 7: 75-7.

5. Aramany MA. Basic principles of obturator design for partially edentulous patients. Part I: classification. J Prosthet Dent. 1978; 40: 554-7.
6. Dable R. A hollow bulb obturator for maxillary resection in a completely edentulous patient. J Clin Diagn Res. 2011; 5: 157-62.

7. Block MS, Baughman DG. Reconstruction of severe anterior maxillary defects using distraction osteogenesis, bone grafts and implants. J Oral Maxillofac Surg. 2005; 63: 291-7.

8. Oh WS, Roumanas E. Dental implant-assisted prosthetic rehabilitation of a patient with a bilateral maxillectomy defect secondary to mucormycosis. J Prosthet Dent. 2006; 96: 88-95.

9. Shaker KT. A simplified technique for construction of an interim obturator for a bilateral total maxillectomy defect. Int J Prosthodont. 2000; 13: 166-8.

10.Zarb G, Hobkirk J, Eckert S, Jacob R. Prosthodontic treatment for edentulous patients. 13th ed. Canada: Elsevier; 2012.

11. Raja HZ, Saleem MN. Gaining Retention, support and stability of a maxillary obturator: a case report. J Coll Physicians Surg Pak. 2011; 21: 31-4. 